\title{
Variations in volumetric erosion rates of bedrock cliffs on a small inaccessible coastal island determined using measurements by an unmanned aerial vehicle with structure-from-motion and terrestrial laser scanning
}

\author{
Hiroyuki Obanawa ${ }^{1,2^{*}}$ (D) and Yuichi S. Hayakawa ${ }^{3}$
}

\begin{abstract}
We conducted topographic measurements using unmanned aerial vehicles and by terrestrial laser scanning at inaccessible sea cliffs with an overhanging complex shape in eastern Japan. From the repeated measurements, we constructed multitemporal three-dimensional point clouds of the sea cliffs to quantitatively evaluate the volumetric changes in the cliffs with a high spatial resolution (in centimeter). As potential main triggers of rockfalls and slope failures, high sea waves and strong earthquakes were examined with the time series of eroded volumes. It is suggested that sea waves have a greater impact than earthquakes on sea-cliff erosion. The approaches provided in this study have great potential for a wide range of applications including high spatial monitoring of other inaccessible, complex-shaped sea cliffs with high data accuracy and low acquisition and operational costs.
\end{abstract}

Keywords: Unmanned aerial vehicle, Terrestrial laser scanning, Point cloud, Sea cliffs, Coastal erosion

\section{Introduction}

Monitoring rapid erosion along a bedrock coast is crucial for the management of infrastructure and conservation of natural landscapes (Sunamura 1992; Hutchinson 2002). In particular, if the bedrock is not sufficiently erosion resistant to preserve the coastline, the loss of land and landscapes can be accelerated with the increasing frequency and potential power of storm waves as a response to rapid climate change (Naylor et al. 2010). Long-term, decadal changes in the bedrock coastlines can be detected by time series of aerial photographs if coastal erosion is sufficiently rapid (Horikawa and

\footnotetext{
*Correspondence: obanawah924@affrc.go.jp

${ }^{1}$ Center for Environmental Remote Sensing, Chiba University, 1-33 Yayoi-cho, Inage-ku, Chiba-shi, Chiba 263-8522, Japan

2Present address: Hokkaido Agricultural Research Center, National Agriculture and Food Research Organization, 1 Hitsujigaoka, Toyohira, Sapporo, Hokkaido 062-8555, Japan

Full list of author information is available at the end of the article
}

Sunamura 1967), but this only allows for the detection of two-dimensional (2D) changes. Three-dimensional (3D) changes, which are necessary to show geomorphological processes acting, can hardly be assessed with such conventional aerial photographs. Recent developments in measurement methodologies including terrestrial laser scanning (TLS) has enabled monitoring of short-term, detailed changes in coastal cliffs (e.g., Lim et al. 2005; Rosser et al. 2005; Kuhn and Prüfer 2014). However, this approach is only possible when there is an appropriate space to establish a measurement device on the seaside such as a breakwater. In many cases, such a place is limited along a bedrock coast.

For assessment of inaccessible areas, recent developments in small unmanned aerial vehicles (UAVs) or system (UAS) combined with structure-from-motion multiview stereo (SfM-MVS) photogrammetry has enabled detailed shape measurements and change detections (e.g., Westoby et al. 2012; Fonstad et al. 2013; 
Obanawa et al. 2014a). The authors reported on the method of operating a small-quadcopter survey system (UAV-SfM) and accuracy of the generated data (e.g., Obanawa et al. 2014b, 2015). Among the advantages of the small-quadcopter survey, it can shoot and measure steep slopes including overhanging portions. Such complex portions can hardly be measured via conventional survey with manned airplanes because the flight height is relatively high and far from the object. In addition, because the running cost of a small UAV is far less and its portability is very high, repetitive measurements over different times are much easier than those of the existing methods.

With these advantages, here, we apply the UAV-SfM approach, combined with TLS, to monitor erosion in inaccessible bedrock sea cliffs with overhanging slopes. In general, erosion in such areas of complex morphology with overhangs is difficult to measure in a $2 \mathrm{D}$ space. To overcome the difficulties in the evaluation of short-term changes in areas with complex morphology, 3D data repeatedly obtained using UAV-SfM and TLS were used to evaluate $3 \mathrm{D}$ volumetric changes in the sea cliffs. The quantified topographic changes of the cliffs were then compared to the potential factors affecting short-term coastal erosion, including the occurrence of significant earthquakes and storm waves.

\section{Methods/Experimental}

\section{Study site}

The study site is in the central part of the sea cliffs around Cape Taitosaki in eastern Chiba prefecture, Japan (Fig. 1). A peninsular-rock, named Suzumejima Island, has a cone-like, circular shape with a diameter of $50 \mathrm{~m}$ and a height of $30 \mathrm{~m}$. Although one side of the island is connected to land during low tide, it is difficult and quite dangerous to climb to it on foot because the surrounding slopes of Suzumejima are very steep. The seaside of the island is therefore invisible and cannot be measured from the land side. The bedrock is composed of alternating Neogene sandstones and mudstones.

With a high retreat rate often exceeding $1 \mathrm{~m} /$ year, sea cliffs around Cape Taitosaki are among the major sources of sediment supply toward the Kujukuri
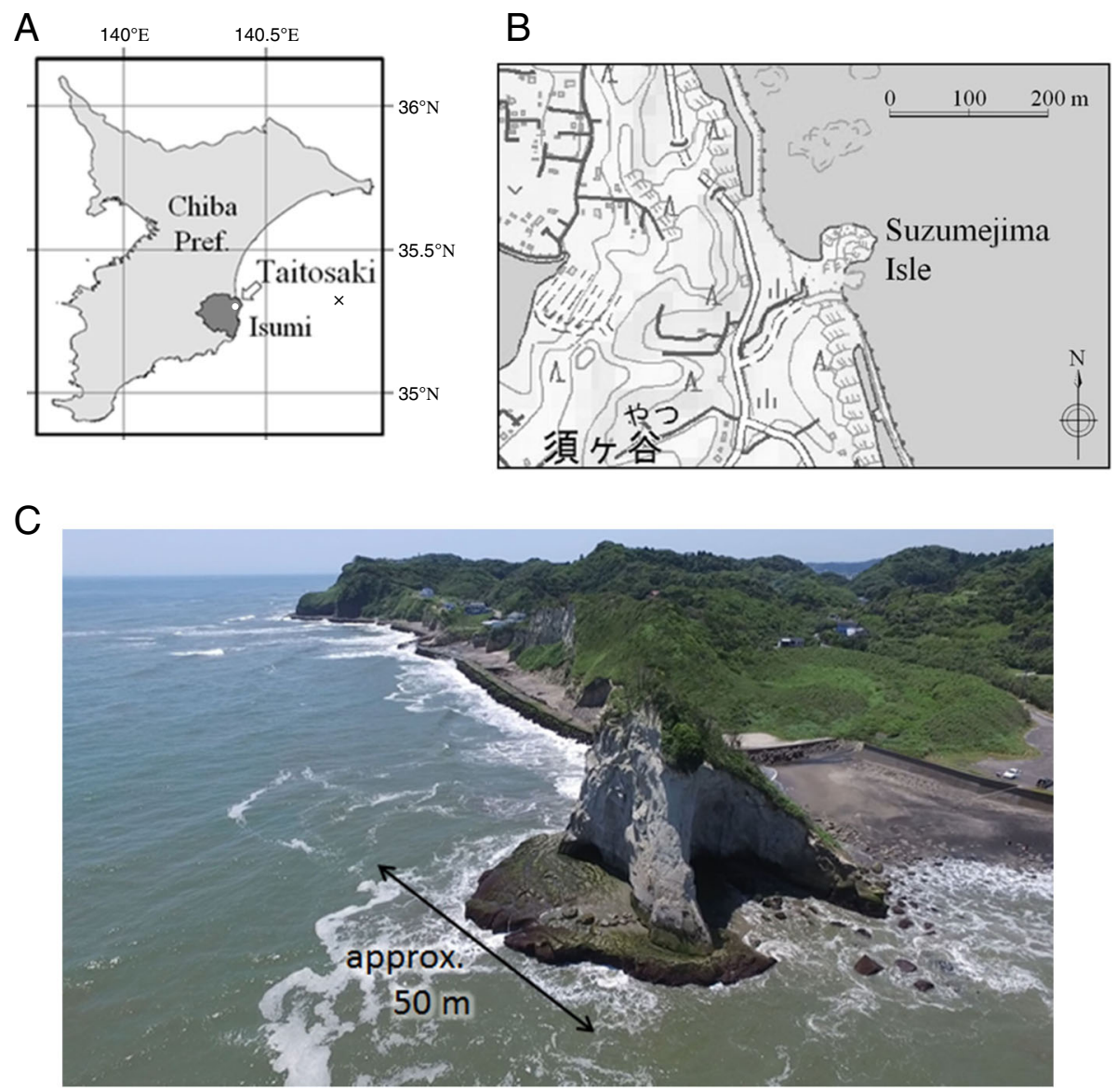

Fig. 1 Location map of the study area $(\mathbf{a}, \mathbf{b})$ and aerial photograph $(\mathbf{c})$ taken by the UAV camera from the north. In $\mathbf{a}$, the white circle is the location of the seismic observation point and the $\mathrm{x}$-mark is the location of the wave observational point 
Coast, on the northern side of the Taitosaki area along the downstream direction of a coastal current (Horikawa and Sunamura 1967). However, artificial embankments have been constructed since the 1960s, which have caused a significant decrease in sea-cliff retreat (Machida 1990; Hoshigami et al. 2006). The drastic decrease in sediment supply has become a major cause of coastal erosion at the Kujukuri sandy beach. The assessment of both long-term and short-term rates of sea-cliff erosion is therefore crucial not only for cliff preservation but also for the management of the sand beach. Because Suzumejima Island is outside of the artificial embankment (Fig. 1c), the island is an unusual place where one can still observe the natural conditions of sea-cliff erosion regardless of the nearby artificial protections.

\section{Data acquisition and analysis}

Field surveys were conducted seven times over 2 years from June 2014 to June 2016 with an interval of approximately 4 months. The inter-measurement periods are defined as period I to VI. During each field campaign, we measured the topography of Suzumejima Island using UAV-SfM and TLS, whose details are described in the following sections. The resultant point cloud data were then post-processed to detect volumetric changes during each period through the timeline of the topographic data.

UAV-SfM was used to capture the entire shape of the island including the seaside, whereas TLS was used to measure the land-side morphology of the island at a higher accuracy. As noted, TLS measurements of coastal cliffs have often been applied to provide an accurate measurement of coastal erosion (Rosser et al. 2005; Kuhn and Prüfer 2014). The photogrammetric UAV-SfM data, on the other hand, can often show greater uncertainties largely depending on the positional accuracies and distribution of ground control points (GCPs) (James and Robson 2014). In this study, we could only establish GCPs on the land near the island, not on the target island itself. The uncertainties of the $3 \mathrm{D}$ point cloud using UAV-SfM can therefore be large on the island. To reduce such uncertainties, we also conducted TLS measurements from the land side at the same time as those recorded using a UAV. Although the TLS data could be obtained only for the land side of the island (i.e., not the entire island), it enabled robust measurements of the relative coordinates of this area with better accuracies than the UAV-SfM clouds. These data were used to rectify the UAV-SfM point cloud which included the sea side of the island. In addition, as the reference for the UAV-SfM point clouds, the
TLS-derived point clouds at different times of measurement were aligned to one another based on a reference period whose coordinates are provided with the highest georeferenced accuracy. This was completed to avoid misalignments because of the decrease in reliability of the control points for a longer period of measurement (time interval between two datasets). The volumetric changes were calculated using the registered UAV-SfM data.

\section{Topographic measurements using UAV-SfM}

For the acquisition of low-altitude aerial photographs, we used small UAVs including the DJI Phantom 2 with a compact camera (Nikon Coolpix A) and the DJI Phantom 3 (Table 1). The camera lens direction was set to be both orthogonal and oblique to the ground to capture the entire terrain of the island with overhanging slopes. We took approximately 300 aerial photographs during each observation. Figure 2 shows an example of the aerial photographs. Detailed structure of vertical cliffs including the overhanging slope facing the sea and fallen rocks on the wave-cut platforms are clearly shown in these photographs. GCPs were placed on the land side of the study site using black and white checkerboard-type targets. These targets are readily identified in the photographs taken using the UAV. The number of GCPs was from three to seven for each measurement. The geographical coordinates of the GCPs were obtained using a global navigation satellite system (GNSS) receiver (Trimble GeoExplorer 6000XH), which is capable of positioning with carrier-phase correction to provide a centimeter-scale accuracy. The base station data of the nearby GNSS stations provided by the Geospatial Information Authority of Japan were used to perform post-processing kinematic correction to the rover data.

Using the UAV-derived photographs and GCP coordinates, topographic data were constructed using the SfM-MVS software (Agisoft PhotoScan Professional). 3D point clouds with red, green, and blue (RGB) colors were the main data derived, whereas the other $2 \mathrm{D}$ data including digital elevation models and orthorectified photographs were not used in this study because the complex shape of the target island cannot be correctly represented in such $2 \mathrm{D}$ data. The outliers in the 3D point clouds were manually removed but vegetation was mostly left as is because the existing filtering algorithms for vegetation are often optimized for 2D-based data and do not work correctly for this dataset.

\section{Topographic measurements using TLS}

We used a long-range scanner (Topcon GLS-1500) and a short-range scanner (Trimble TX5) with measurement accuracies on the order of millimeters. These scanners were used together from multiple observation points. Internal registrations, i.e., the alignments of two or more 
Table 1 Specifications of the UAVs

\begin{tabular}{|c|c|}
\hline \multicolumn{2}{|l|}{ Phantom 2 and COOLPIX A } \\
\hline \multicolumn{2}{|l|}{ UAV specifications } \\
\hline Product name & DI Phantom 2 \\
\hline Aircraft class & Quadcopter \\
\hline Dimensions & $350 \times 350 \times 190 \mathrm{~mm}$ \\
\hline Weight & $1000 \mathrm{~g}$ \\
\hline Max flight speed & $15 \mathrm{~m} / \mathrm{s}$ \\
\hline Max ascent/descent speed & $6 \mathrm{~m} / \mathrm{s}$ \\
\hline Communication distance & 1000 m \\
\hline Max flight time & $25 \min$ \\
\hline Payload & $400 \mathrm{~g}$ (empirical value) \\
\hline \multicolumn{2}{|l|}{ Camera specifications } \\
\hline Product name & Nikon COOLPIX A \\
\hline Pixels & 16.2 million \\
\hline Image sensor & $23.6 \times 15.6 \mathrm{~mm}$ \\
\hline Dimensions & $111.0 \times 64.3 \times 40.3 \mathrm{~mm}$ \\
\hline Weight & $299 \mathrm{~g}$ \\
\hline Interval shooting & More than $1 \mathrm{~s}$ \\
\hline \multicolumn{2}{|l|}{ Phantom 3} \\
\hline \multicolumn{2}{|l|}{ UAV specifications } \\
\hline Product name & Dار Phantom 3 advanced \\
\hline Aircraft class & Quadcopter \\
\hline Dimensions & $350 \times 350 \times 193 \mathrm{~mm}$ \\
\hline Weight & $1280 \mathrm{~g}$ \\
\hline Max flight speed & $16 \mathrm{~m} / \mathrm{s}$ \\
\hline Max ascent/descent speed & $5 / 3 \mathrm{~m} / \mathrm{s}$ \\
\hline Communication distance & $2000 \mathrm{~m}$ \\
\hline Max flight time & $23 \mathrm{~min}$ \\
\hline Payload & $0 \mathrm{~g}$ \\
\hline \multicolumn{2}{|l|}{ Camera specifications } \\
\hline Product name & DJI FC300S \\
\hline Pixels & 12.4 million \\
\hline Image sensor & $6.16 \times 4.62 \mathrm{~mm}$ \\
\hline Dimensions & Connected to the UAV \\
\hline Weight & Part of the UAV \\
\hline Interval shooting & More than $2 \mathrm{~s}$ \\
\hline
\end{tabular}

point clouds from different scan positions, for each scanner and among scanners were implemented using the iterative closest point (ICP) method (Besl and McKay 1992; Teza et al. 2007). The ICP method uses points in the same area of two point clouds in which the characteristic morphological features common to both clouds are present. One cloud is slightly moved to another reference cloud to reduce the mean distance between the closest points. This procedure is then
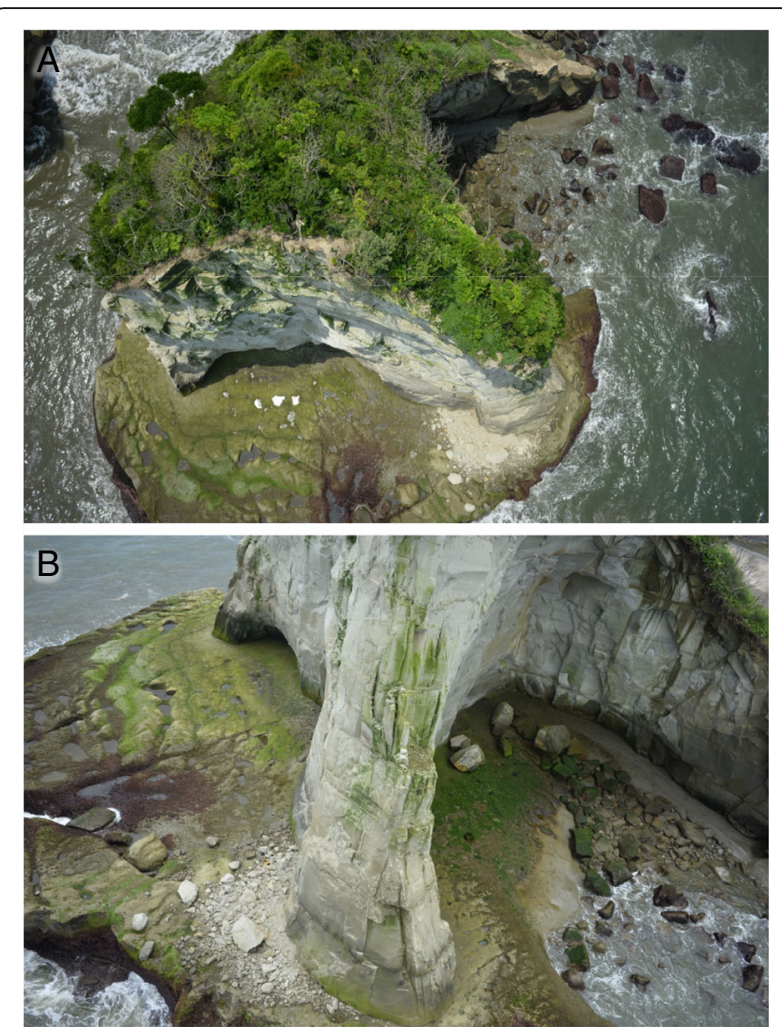

Fig. 2 Examples of aerial photographs of Suzumejima taken by UAV on June 17, 2015. a Taken from above the island (west on top) and b ) taken from the north

iterated to minimize the distances. The internally registered point cloud is then georeferenced using the GCPs for each time of measurements. The GCPs were the same for both the UAV-SfM and TLS data. We performed initial filtering of outliers in the TLS-derived point clouds but did not remove the vegetation during this stage.

Because the georeferenced clouds still comprise absolute positional uncertainties on the order of $10^{0}-10^{1} \mathrm{~cm}$ because of the uncertainties in the GNSS measurements, we further refined the external registration using the ICP method for the time series of TLS point clouds. Among the georeferenced TLS point clouds, that with the least uncertainty was selected as the reference. Point clouds immediately before or after the reference cloud are registered to the reference, and the other clouds are then successively registered to the previous or following cloud. The ICP registration requires unchanged features in both clouds. To exclude changed areas, the overlaps of two georeferenced point clouds were investigated in detail. First, areas with large differences, including vegetation, sand deposits, and apparently missing bedrock, were manually excluded from both the moving and 


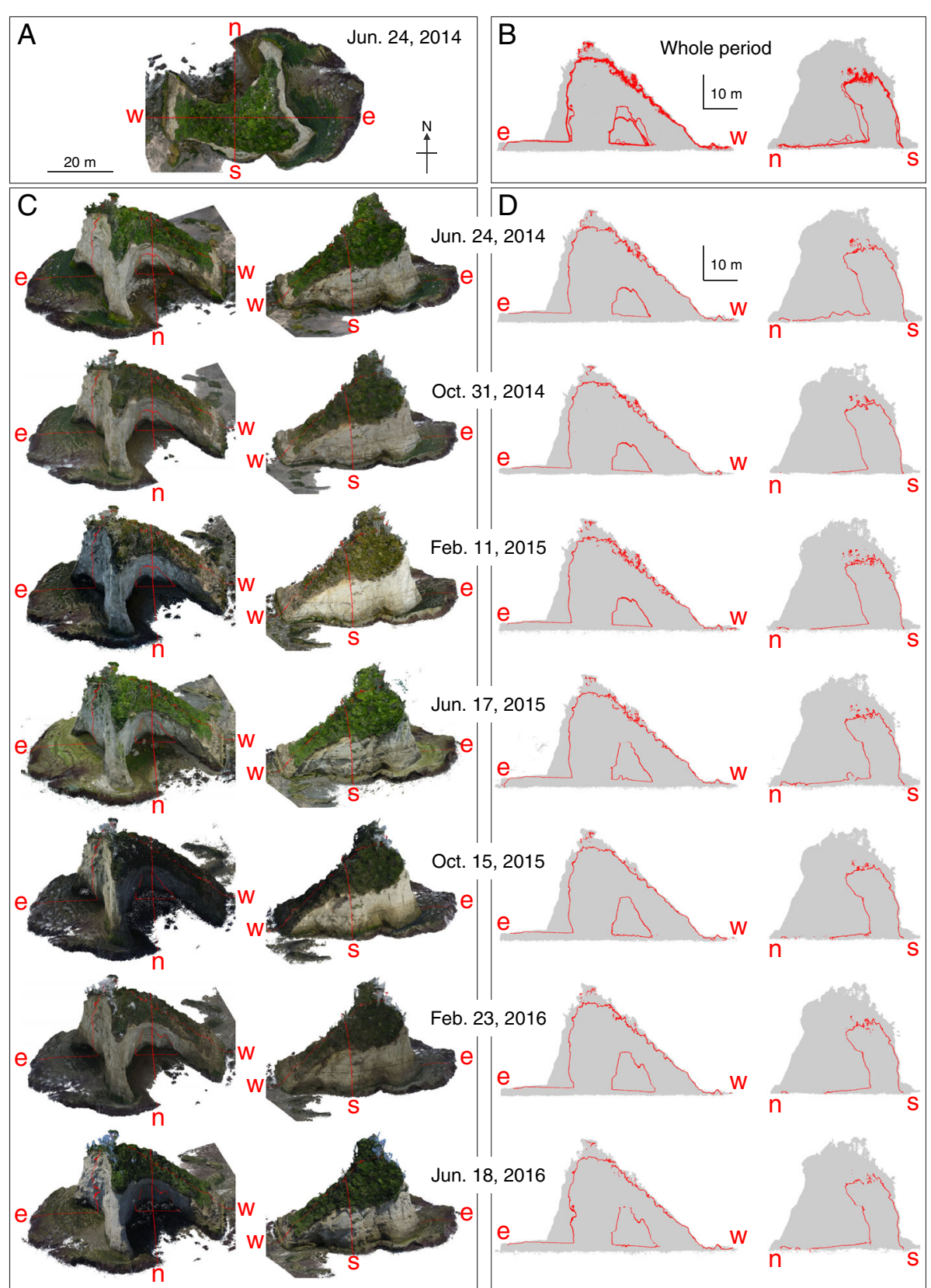

Fig. 3 3D models (a, c) and cross sections (b, d) of Suzumejima from June 24, 2014, to June 18, 2016. a Viewed from the top and $\mathbf{c}$ viewed obliquely from above with traverse lines (red lines) of cross sections. Lowercase letters ( $n, s, e$, and w) indicate the directions of traverse lines. The left figures of $\mathbf{c}$ are viewed from the north, and the right figures are viewed from the south. $\mathbf{b}$ Superimposed cross sections of all periods (d). The left figures of $\mathbf{d}$ show cross sections of an east-west orientation, and the right figures show cross sections of a north-south orientation

reference clouds. Second, ICP registration was performed once on the moving cloud. Third, the overlaps were checked automatically and points in overlapping areas were left. The second and third procedures were then repeated from one to several times to minimize the mean closest point-to-point distance between the point clouds.
The TLS-derived point clouds registered in the timeline were then used as the reference for the UAV-SfM clouds. A point cloud using UAV-SfM was aligned to that using TLS for the same measurement time, following the same procedure of ICP as previously described type. The externally registered UAV-SfM point clouds were used for the following analyses. 


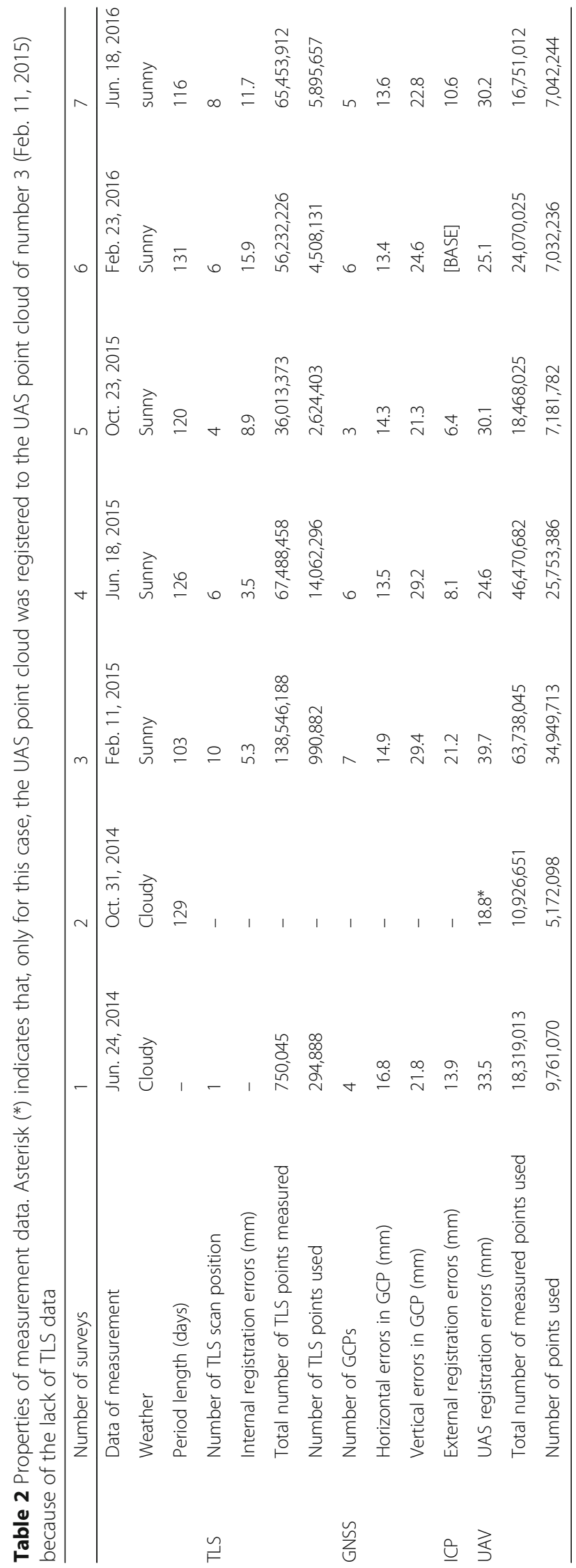




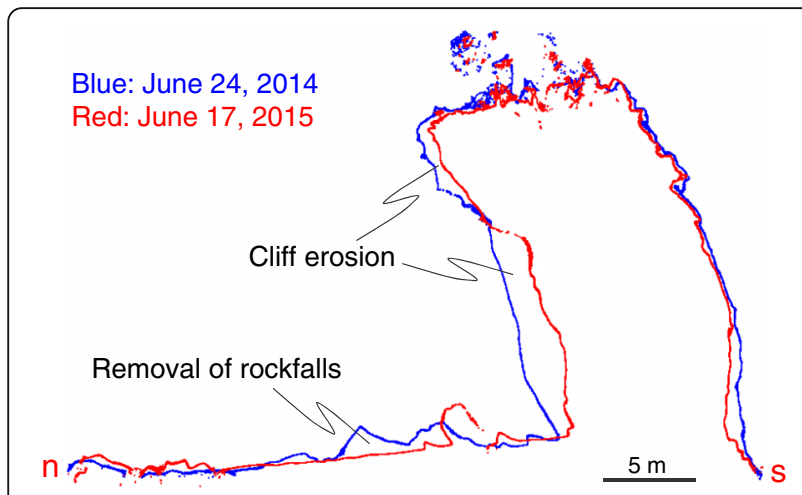

Fig. 4 Cliff erosion between June 24, 2014, and June 17, 2015, on the cross section in Fig. 3

\section{Detection of changed areas}

We calculated the volume of eroded bedrock during a period by constructing 3D polygonal models of changed areas from paired point clouds before and after the change. The procedure of volume estimation is described in the following paragraph.

First, normals of the surface in point cloud for each measurement time were calculated to explicitly define the surface orientation of the target bedrock. The distances between the nearest points in the two, before and after point clouds, during a period were computed for both clouds using the cloud-to-cloud (C2C) distance function in the CloudCompare software. Points having more than a certain C2C distance (exceeding the level of change detection, which is regarded to be spatially uniform and sufficiently larger than the registration errors) were extracted from both the before and after clouds. The normals of the cloud after the change were then set inversely to represent the surface orientation of missing volume blocks. The volumetric polygonal models of the missing areas could then be generated from the extracted points both before and after clouds with surface normal for the blocks, using the function of Poisson surface reconstruction in CloudCompare (Kazhdan et al. 2006). Although the unchanged areas were effectively removed even if the original data was unfiltered, the resultant volumetric polygonal models often comprise bulky meshes showing errors including vegetation and uncertain polygons on the rock surfaces. Therefore, we visually inspected the polygons, as well as the original point clouds before and after the change, to check whether the polygons show actual changes or not. The remaining erroneous polygons were then manually removed. The total volume of the remaining polygons was finally obtained for each period.

As a result, although the uncertainty derived from the registration errors (typically several centimeters to decimeters) remained, the total volume of missing rock blocks due to erosional changes was obtained from the point clouds before and after the change during each period. Although very small changes that did not exceed the level of detection could not be counted, the major changes that largely contributed to the total volume of the changes were captured.

\section{Results and discussion}

\section{Time series of 3D point clouds}

We successfully obtained detailed topographic data of Suzumejima Island with the integrated approach using UAV-SfM and TLS (Fig. 3, Table 2). The 3D topographic data have characteristics of significantly higher spatial and temporal resolution than that of the existing data such as aerial photographs from a manned airplane. The uncertainty in the registration of the UAV-derived point clouds (mean point-to-point distances between two overlapping clouds) ranged from 20 to $40 \mathrm{~mm}$ (Table 2).

The 3D data shows detailed topographic features, including a ceiling of the sea cave, a vertical cliff on the east side, and flat areas of the wave-cut bench and floor of the sea cave. In addition, we could obviously recognize bedrock erosion via rockfalls, as well as the removal of accumulated rock blocks beneath the cliff. By creating a topographic profile using the $3 \mathrm{D}$ data, we found that the base of the island has thinned because of the intense erosion at the sea cave and that the island has been destabilized as a whole (Fig. 4). These results demonstrate the high potential of this type of survey method mainly composed of UAV measurements for $3 \mathrm{D}$ data acquisition of higher spatial resolution in such an inaccessible coastal area.

Figure $5 \mathrm{c}$ shows the eroded volumes for each period derived from the difference in the $3 \mathrm{D}$ point clouds. Assuming that we can detect changes more than twice the value of the registration errors (up to $40 \mathrm{~mm}$ as previously noted), the level of detection for the volume calculation was set as $100 \mathrm{~mm}$. Eroded volumes varied from a minimum of $10.6 \mathrm{~m}^{3}$ during period II to a maximum of $178.5 \mathrm{~m}^{3}$ during period IV (an average of $96.9 \mathrm{~m}^{3}$ ), resulting in a total loss of $581.5 \mathrm{~m}^{3}$. The erosion rate for the whole island varied from 2.5 to $36.5 \mathrm{~cm} /$ year, an approximately 15 times difference. The total volume of the island, measured after removing vegetation, was approximately $13,000 \mathrm{~m}^{3}$ in June 2014, and the volumetric percentage of erosion for each period was calculated to be from 0.1 to $1.4 \%$. The total loss of volume over the 2 years was $4.5 \%$, suggesting that the island will disappear in approximately 45 years if erosion continues at the same pace. This is plausible because the island has been intensively eroded during recent decades as shown in historical aerial photographs. 

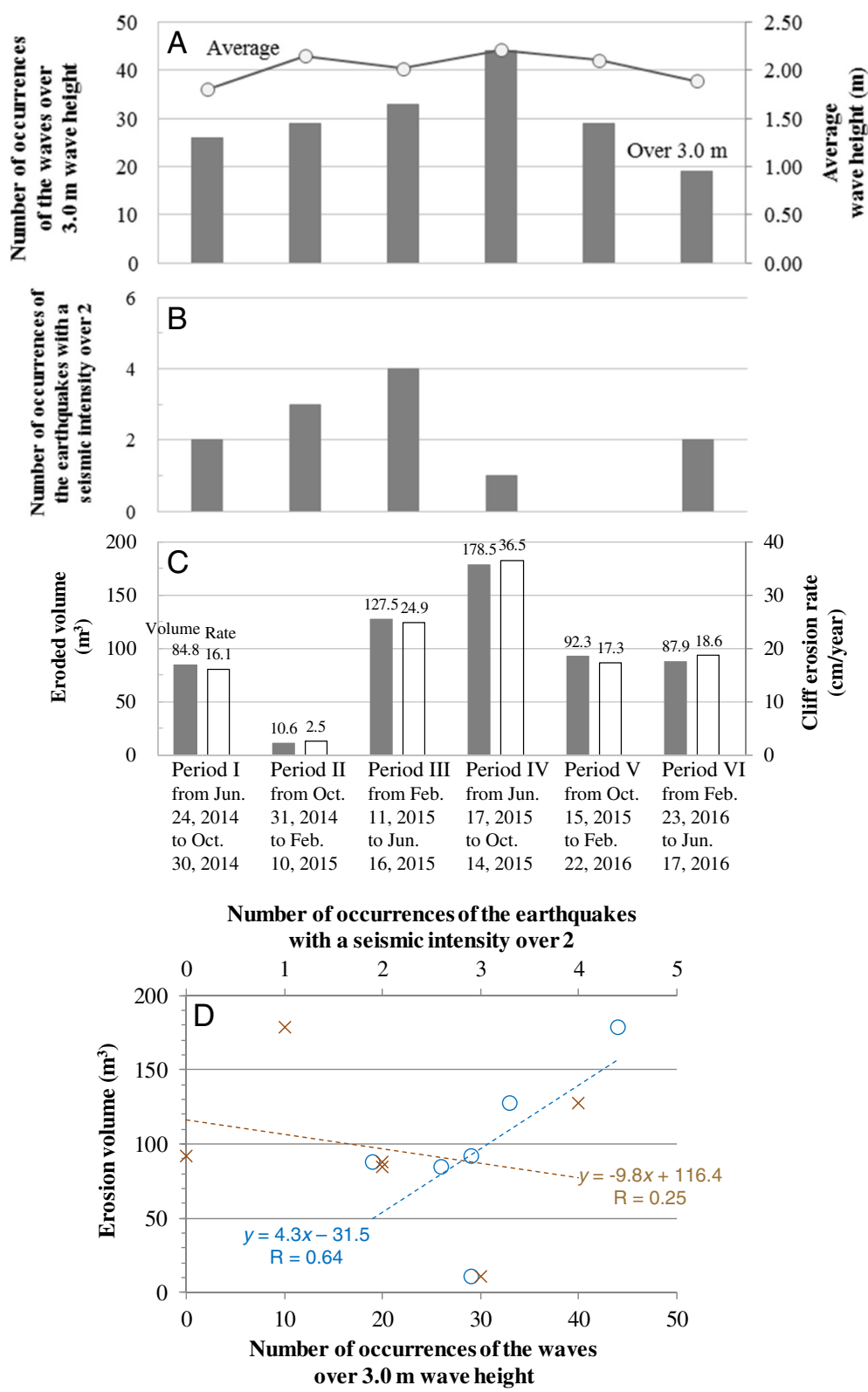

Fig. 5 Changes in the occurrences of potential triggering factors and cliff erosion between survey periods. a Wave height at Bosohanto-oki. b Earthquake at Choja, Misaki-machi, Ishumi-shi. c Erosion rate of the cliff. d Relationships between potential triggering factors and eroded volume. Blue-colored circles are wave datasets and brown-colored $x$-marks are earthquake datasets

\section{Triggering factors affecting erosion}

Glancing the temporal changes in erosion volume, seasonal variations in erosion rates were not clear (Fig. 5c). Here, as potential main triggers of rockfall and slope failure, we focus on sea wave conditions and earthquake occurrences (e.g., Young et al. 2009, 2013; Brain et al. 2014; Vann Jones et al. 2015; Earlie et al. 2015).

Estimated daily ( 9 a.m. and 9 p.m.) values of significant wave height at the observation point nearest to the study site (Bosohanto-oki, $35^{\circ} 20^{\prime} \mathrm{N}, 140^{\circ} 45^{\prime} \mathrm{E}$ ) are shown in
Fig. 5a. Observational records were obtained from the climate and ocean database of the Japan Meteorological Agency (2017). The average wave height was approximately $2.0 \mathrm{~m}$ during the entire observational period, and the maximum height was $5.9 \mathrm{~m}$ on October 6, 2014. Average wave heights during each observational period varied from 1.8 to $2.2 \mathrm{~m}$ and did not show clear annual trends in its variation. The number of occurrences of a wave height greater than $3.0 \mathrm{~m}$ during each period was a maximum of 44 times during period IV and a minimum of 19 times during period VI, 
whose difference was more than two times. If compared to erosion volume (Fig. 5c), both values of erosion volume and high-wave occurrence have a peak during period IV and show relatively good correspondence to one another, with an exceptional case during period II (Fig. 5d). Although a threshold value of wave height affecting cliff erosion should vary depending on the observational period and/or study site, we preliminarily presumed it to be $3.0 \mathrm{~m}, 1.5$ times the average and one-half of the maximum wave height in this case. Further studies are needed to decide a threshold value of effective wave height.

Figure $5 \mathrm{~b}$ shows the number of occurrences of large earthquakes of a seismic intensity scale from the earthquake database of the Japan Meteorological Agency (2017) greater than two during each period at the nearest seismic observational point (Choja, Misaki-machi, Ishumi-shi, $35^{\circ} 18^{\prime} \mathrm{N}, 140^{\circ} 23^{\prime} \mathrm{E}, 3.1 \mathrm{~km}$ southwest of the study site). The Japanese Seismic Scale cannot be converted to the Modified Mercalli Intensity Scale because of the difference in the calculation method. Observational records were obtained from the earthquake database of the JMA (2017). During the period of June 24, 2014, to June 17, 2016, the maximum intensity was four (May 30, 2015). The number of occurrences was a maximum of four times during period III and a minimum of zero times during period $\mathrm{V}$. When compared to the temporal change in the eroded volumes (Fig. 5c), a correspondence between these values was unclear. For example, although a maximum erosion volume $\left(178.5 \mathrm{~m}^{3}\right)$ was recorded during period IV, the number of occurrences of an earthquake with a seismic intensity greater than two on the Japanese Scale was relatively few (two times). In conclusion, it is suggested that sea waves have a greater impact than earthquakes in regard to triggering rockfalls.

\section{Conclusions}

Using repeated UAV-SfM and TLS measurements for 2 years from June 24, 2014, to June 18, 2016, multitemporal 3D models of the sea cliffs were constructed, and the topographic changes of high spatial resolution were clarified. Erosional rates were not constant but varied up to approximately 15 times depending on the period, from 2.5 to $36.5 \mathrm{~cm} /$ year, although seasonal variances between the summer and winter seasons were unclear. As the potential main triggers of rockfall and slope failure, we examined the occurrences of high sea waves and significant earthquakes. The average wave height was approximately $2.0 \mathrm{~m}$ and the wave height maximum value was $5.9 \mathrm{~m}$. The number of occurrences of a wave height greater than $3.0 \mathrm{~m}$ showed relatively good correspondence with the time series of eroded volume. On the other hand, the number of occurrences of an earthquake of a seismic intensity greater than two on the Japanese
Scale did not show a clear correspondence with the eroded volume. In conclusion, it is suggested that sea waves have a greater impact than earthquakes in terms of triggering sea-cliff erosion. However, this result is based on a comparison during a relatively short period of time of 2 years. Further observational data for longer time periods should lead to a more concrete discussion. In addition, not only the external triggering factors but also conditional factors such as weakening bedrock strength due to weathering, lithological weakness, and structural weakness depending on the 3D shape of the island should be further considered from the viewpoint of immunity to mass movement.

\section{Abbreviations}

GCPs: Ground control points; GNSS: Global navigation satellite system; ICP: Iterative closest point; MVS: Multiview stereo; RGB: Red, green, and blue; SfM: Structure from motion; TLS: Terrestrial laser scanning; UAV: Unmanned aerial vehicle

\section{Acknowledgements}

This work is a part of the Joint Research by the Center for Spatial Information Science (CSIS), The University of Tokyo.

\section{Funding}

This work was supported by JSPS KAKENHI Grant Numbers JP25702014, JP25750148, JP17H02031 and JP16KK0012.

\section{Availability of data and materials \\ A part of the data used in this paper is available from the Joint Research Assist System (JoRAS), The University of Tokyo.}

\section{Authors' contributions}

$\mathrm{HO}$ conducted field measurements using an UAV and drafted this manuscript. YSH performed TLS measurements in the field and data analysis and drafted this manuscript. Both authors read and approved the final manuscript.

\section{Competing interests}

The authors declare that they have no competing interests.

\section{Publisher's Note}

Springer Nature remains neutral with regard to jurisdictional claims in published maps and institutional affiliations.

\section{Author details}

${ }^{1}$ Center for Environmental Remote Sensing, Chiba University, 1-33 Yayoi-cho, Inage-ku, Chiba-shi, Chiba 263-8522, Japan. ${ }^{2}$ Present address: Hokkaido Agricultural Research Center, National Agriculture and Food Research Organization, 1 Hitsujigaoka, Toyohira, Sapporo, Hokkaido 062-8555, Japan. ${ }^{3}$ Center for Spatial Information Science, The University of Tokyo, 5-1-5 Kashiwanoha, Kashiwa, Chiba 277-8568, Japan.

Received: 2 July 2017 Accepted: 25 May 2018

Published online: 19 June 2018

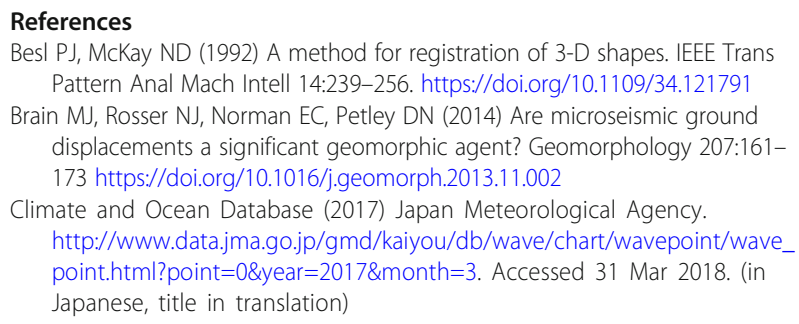


Earlie CS, Young AP, Masselink G, Russell PE (2015) Coastal cliff ground motions and response to extreme storm waves. Geophys Res Lett 42: 847-854. https://doi.org/10.1002/2014GL062534

Earthquake Database (2017) Japan Meteorological Agency. http://www.data.jma. go.jp/svd/eqdb/data/shindo/. Accessed 31 Mar 2018. (in Japanese, title in translation)

Fonstad MA, Dietrich JT, Courville BC, Jensen JL, Carbonneau PE (2013) Topographic structure from motion: a new development in photogrammetric measurement. Earth Surf Process Landf 38:421-430

Horikawa K, Sunamura T (1967) Study on recession of sea cliffs using aerial photographs. Annu J Coast Eng JSCE 14:315-324. https://doi.org/10.11532/proce1955.14.315 (in Japanese)

Hoshigami Y, Uda T, Noshi Y, Ozawa H (2006) Investigation of origin of littoral forming Kujukuri coast plane. Proc Civ Eng Ocean 22:403-408 (in Japanese, title in translation)

Hutchinson JN (2002) Chalk flows from the coastal cliffs of north-west Europe In: Evans SG, JV DG (eds) Catastrophic landslides: effects, occurrence, and mechanisms. Geological Society of America, Boulder, pp 257-312

James MR, Robson S (2014) Mitigating systematic error in topographic models derived from UAV and ground-based image networks. Earth Surf Process Landf 39:1413-1420. https://doi.org/10.1002/esp.3609

Kazhdan M, Bolitho M, Hoppe H (2006) Poisson surface reconstruction. Proc Symp Geom Process:61-70. https://doi.org/10.1145/1364901.1364904.

Kuhn D, Prüfer S (2014) Coastal cliff monitoring and analysis of mass wasting processes with the application of terrestrial laser scanning: a case study of Rügen, Germany. Geomorphology 213:153-165. https://doi.org/10.1016/j. geomorph.2014.01.005

Lim M, Petley DN, Rosser NJ, Allison RJ, Long AJ, Pybus D (2005) Combined digital photogrammetry and time-of-flight laser scanning for monitoring cliff evolution. Photogramm Rec 20:109-129

Machida H (1990) Topographic effects of artificial structures on Kujukuri coast. Graduation thesis, University of Tsukuba, Tsukuba (in Japanese, title in translation)

Naylor LA, Stephenson WJ, Trenhaile AS (2010) Rock coast geomorphology: recent advances and future research directions. Geomorphology 114:3-11

Obanawa H, Hayakawa YS, Gomez C (2014a) 3D modelling of inaccessible areas using UAV-based aerial photography and structure from motion. Trans Jpn Geomorphological Union 35:283-294 (in Japanese, title in translation)

Obanawa H, Hayakawa YS, Kato A, Gomez C (2015) Simplified survey method using small UAV and single-point positioning GNSS equipped digital camera. Tran Jpn Geomorphological Union 36:87-106 (in Japanese, title in translation)

Obanawa H, Hayakawa YS, Saito H, Gomez C (2014b) Comparison of DSMs derived from UAV-SfM method and terrestrial laser scanning. Japan Soc Photogrammetry Remote Sensing 53:67-74 (in Japanese, title in translation)

Rosser NJ, Petley DN, Lim M, Dunning SA, Allison RJ (2005) Terrestrial laser scanning for monitoring the process of hard rock coastal cliff erosion. Q J Eng Geol Hydrogeol 38:363-375. https://doi.org/10.1144/1470-9236/05-008

Sunamura T (1992) Geomorphology of rocky coasts. Wiley, Chichester

Teza G, Galgaro A, Zaltron N, Genevois R (2007) Terrestrial laser scanner to detect landslide displacement fields: a new approach. Int J Remote Sens 28:34253446. https://doi.org/10.1080/01431160601024234

Vann Jones EC, Rosser NJ, Brain MJ, Petley DN (2015) Quantifying the environmental controls on erosion of a hard rock cliff. Mar Geol 363:230-242 https://doi.org/10.1016/j.margeo.2014.12.008

Westoby MJ, Brasington J, Glasser NF, Hambrey MJ, Reynolds JM (2012) "Structure-from-motion" photogrammetry: a low-cost, effective tool for geoscience applications. Geomorphology 179:300-314

Young AP, Guza RT, Dickson ME, O'Reilly WC, Flick RE (2013) Ground motions on rocky, cliffed, and sandy shorelines generated by ocean waves. J Geophys Res Oceans 118:6590-6602. https://doi.org/10.1002/2013JC008883

Young AP, Guza RT, Flick RE, O'Reilly WC, Gutierrez R (2009) Rain, waves, and short-term evolution of composite seacliffs in southern California. Mar Geol 267:1-7 https://doi.org/10.1016/j.margeo.2009.08.008

\section{Submit your manuscript to a SpringerOpen ${ }^{\circ}$ journal and benefit from:}

- Convenient online submission

- Rigorous peer review

- Open access: articles freely available online

- High visibility within the field

- Retaining the copyright to your article

Submit your next manuscript at $\boldsymbol{\nabla}$ springeropen.com 